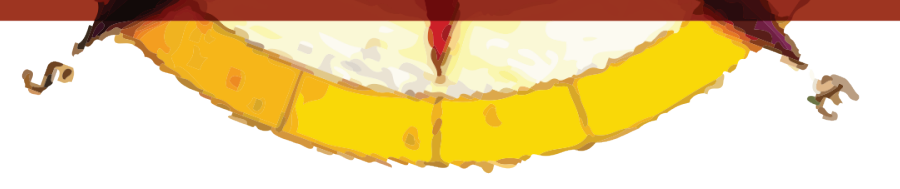

\title{
SECUENCIAS DE CIENCIAS SOCIALES (GEOGRAFÍA). LOS ESPACIOS RURALES Y LAS ACTIVIDADES ECONÓMICAS, BUENOS AIRES, EDITORIAL BIBLOS, 2011
}

\author{
AUTOR: RIMA JUAN CARLOS
}

Reseña elaborada por: María Victoria Fernández Caso ${ }^{1}$

\section{RESUMEN}

El libro que se reseña forma parte de una nueva colección: Secuencias para la Enseñanza de la Editorial Biblos, que está destinada a docentes de nivel secundario y aborda temas centrales del currículum en las distintas áreas de conocimiento. Se trata de una colección que ofrece a los profesores en ejercicio, un conjunto de actividades para el aula que, desde un enfoque crítico, permiten el abordaje de los contenidos curriculares desde criterios de problematización, contextualización y complejización creciente. Incluyen una variedad de fuentes de información, consignas de trabajo grupales e individuales y sugerencias para organizar el trabajo de aula.

\section{RESEÑA}

La propuesta para la asignatura Geografía de esta Colección se titula Secuencias de Ciencias Sociales (Geografia) Los espacios rurales y las actividades económicas, su autor es el Profesor Juan Carlos Rima, geógrafo y docente de la Universidad de Buenos Aires, con amplia experiencia en la enseñanza del nivel medio, es autor también de manuales escolares y otros materiales curriculares.

Una primera característica a destacar en este libro, se refiere al enfoque disciplinar socio-crítico adoptado en el análisis de los problemas rurales, que recoge los más recientes aportes provenientes del campo académico. En efecto, el autor presenta de manera clara y fundamentada el marco teórico en el que encuentra sentido el recorte didáctico propuesto, es decir el problema o contenido a analizar y los procedimientos seleccionados para su abordaje. Entre los principales conceptos estructurantes, es decir los de mayor nivel de abstracción, el autor hace foco en los conceptos de espacio geográfico, territorio, actores o grupos sociales, historicidad de los fenómenos geográficos, capitalismo, etc. Más específicamente, autores como David Harvey, Eduardo Gudynas, Maristella Svampa, Carlos Reboratti, Humberto Campodónico o Miguel Teubal, entre otros, son retomados

Profesora en Geografía- Universidad de Buenos Aires. 
en el desarrollo del texto de actualización temático-conceptual, ofreciendo a los docentes nuevas coordenadas teóricas desde las que abordar estas problemáticas. Así nociones como acumulación por desposesión, nueva agricultura, frontera agropecuaria, megaminería, reprimarización o neoextractivismo, orientan el desarrollo de las secuencias de actividades, permitiendo así acercar a los alumnos un discurso complejo, plural y contrastado sobre los problemas socio territoriales de los espacios rurales latinoamericanos.

En la primera parte del libro, el autor presenta las problemáticas del agro y de la minería actual, en el marco del desarrollo del capitalismo global y de la adopción de políticas neoliberales en América Latina. Una de estas problemáticas, de carácter multidimensional, es la que se vincula con la "nueva" agricultura o modernización agrícola, que incluye cambios de carácter técnico en el destino de la producción, en las relaciones sociales del campo, en la aparición de nuevos sujetos y nuevas heterogeneidades y también en el papel del Estado. En las siguientes páginas, Juan Carlos Rima delinea las distintas dimensiones de esta modernización, empezando por la que se refiere a la aparición de los nuevos sujetos de inversión, con suficiente capital financiero disponible, que buscan oportunidades para rentabilizar su capital. El autor destaca el papel de "pooles de siembra", que organizan la producción agropecuaria a partir de su poder financiero, el control de las distintas etapas del circuito y el conocimiento del funcionamiento de los mercados mundiales. Otra dimensión abordada, se refiere a la tendencia a la monoproducción como respuesta de los países de América del Sur a las nuevas condiciones de los mercados, que se expresa en la especialización en la agricultura sojera destinada a la producción de forrajes (alimento para el ganado de los países importadores). A continuación el autor focaliza en tres condiciones centrales: siembra directa, biotecnología y nuevas maquinarias, que conforman el pilar o tríada tecnológica de esta nueva agricultura. Como el componente sensible o estratégico de la tríada es la dimensión biotecnológica, se explica aquí también las formas en que las empresas propietarias, como Monsanto y Dupont, son las que dominan el circuito de producción. Finalmente se aborda el problema de la inseguridad alimentaria, como un problema asociado a la nueva etapa de desarrollo capitalista y a la modalidad que ésta adquiere en los espacios rurales en América latina.

A continuación, se presenta la sección dedicada a esbozar un panorama de otra de las actividades extractivas clave en la región: la minería. Se afirma que se trata de un tipo de producción que integra el grupo de actividades primarias o de bajo grado de elaboración, a través de la cual la región se insertó históricamente en la economía mundial. De ahí que el autor sostenga que los modelos de desarrollo latinoamericano basados en el extractivismo, son una constante en su historia. A fin de remarcar la relevancia y signficatividad de tratar estos temas en las aulas de la escuela secundaria, se pondera la muy elevada magnitud con la que opera la minería metalífera en la actualidad en América Latina, observada en la superficie afectada a la explotación, los flujos globales que genera, las inversiones que se realizan, los volúmenes mineros extraídos, los montos exportados y las transformaciones socio territoriales que producen en la escala local. Es claro que estos y otros aspectos de la megaminería a cielo abierto, pueden ser pensados como problemas de enseñanza de alta relevancia socio política, y en consecuencia como portadores de contenidos para la formación ciudadana. En este sentido, el autor elige desarrollarlos desde las siguientes entradas temáticas: La megaminería como enclave geográfico; La megaminería y su aporte a la economía de América Latina; Los problemas a escala local; La megaminería y el problema ambiental: La megaminería y la población local. 
En el siguiente apartado, titulado "Claves pedagógicas: acerca de la perspectiva didáctica adoptada" el autor explicita las decisiones adoptadas en la selección de contenidos para el desarrollo de las secuencias didácticas. Así, del conjunto de actividades productivas que se desarrollan en los espacios rurales, Rima realiza un recorte para concentrarse en las transformaciones que en las últimas dos décadas se están produciendo en las actividades agropecuarias y mineras de la región. Luego de una panorámica general de ambos tipos de actividades, se realiza un nuevo recorte para profundizar en las transformaciones que operan en la agricultura de cereales y oleaginosas, en la ganadería bovina, y en la minería metalífera. Estos recortes, sostiene Rima, tienen sentido porque se trata de transformaciones productivas en las que confluyen múltiples dimensiones, como las sociales, económicas, territoriales y ambientales. Los recortes propuestos por el autor, permiten el interjuego de escalas geográficas y de conceptos de distinto nivel de generalidad. Así, tenemos las siguientes pistas temático-conceptuales para el trabajo con las actividades propuestas en las secuencias:

1) Se establecen vínculos entre las escalas global-regional-nacional y local, de modo que se pueden trabajar las distintas formas de articulación entre los procesos de mayor escala (en este caso la global) y los de escalas más acotadas. Subyace en este interjuego el concepto de desigualdad geográfica, en tanto que frente a procesos macro, las sociedades de los distintos espacios generan en los espacios geográficos respuestas a partir de su propia historia. También permite establecer qué rasgos son comunes a la escala supranacional (en este caso América Latina) y cuáles son propios de la escala nacional-local. Por ejemplo, frente al continuo crecimiento de la demanda mundial de materias primas con escaso grado de elaboración la respuesta de América Latina es un incremento de la producción destinada a la exportación; esto lleva a la transformación de los espacios de producción. Pero, además, cada país, y aun cada lugar, produce sus propias respuestas a esa demanda. Así, si el crecimiento de la producción del agro para atender a la demanda mundial es la respuesta unificadora de la región, existen diferencias a su interior: expansión sojera en el ámbito templadosubtropical y desarrollo ganadero en los tropicales-ecuatoriales.

2) Los conceptos de mayor nivel de abstracción, como espacio geográfico, actores socio-económicos, dimensión histórica, ambiente y dinámica capitalista, adquieren en la secuencia una doble significación. Por un lado, porque guían el abordaje de los problemas propuestos. Por el otro, porque se expresan en conceptos de menor nivel de abstracción, que permiten comprender las tensiones y conflictos que transforman a esos espacios. Por ejemplo, al estudiar el problema de la minería metalífera en torno al cerro Careperro en Colombia el nivel de generalización se concreta en el reconocimiento de tres principales actores en conflicto: las poblaciones aborígenes, las empresas multinacionales de minería y el Estado colombiano. El primero de los grupos valora el área en disputa según el carácter religioso-cultural que se le asigna al cerro. Para las empresas multinacionales, el cerro es visto como un yacimiento de oro. Para el Estado colombiano, la minería en gran escala es un pilar de su política económica. De aquí se desprendan objetivos distintos y hasta antagónicos de cada actor en relación al cerro. La forma en que se resuelva el problema derivará en una particular transformación del área. Un caso de estas características permitiría "volver" al concepto más abstracto, para generalizar la idea de la existencia de tensiones o conflictos entre actores.

Otras problemáticas que se abordan a lo largo de las secuencias son:

- Nuevos actores socioeconómicos de escala nacional y global.

- Nuevos y viejos conflictos con nuevos y viejos actores. 
- Nuevas áreas dinámicas y nuevas formas productivas en el capitalismo global.

- Expansión de la frontera agropecuaria y el problema ambiental.

- Del policultivo al monocultivo y su relación con la inseguridad alimentaria.

- La reprimarización de la economía latinoamericana como modelo de inserción global.

- La agriculturización, la expansión ganadera y la sojización.

- El avance de una agricultura sin agricultores y la reducción de la población rural.

- El circuito productivo y el dominio de las empresas multinacionales de biotecnología.

- Formas de apropiación y destino de la renta minera.

Una apropiación de conceptos y contenidos de Geografía que permita a los alumnos acercarse a la comprensión de las transformaciones socio-territoriales requiere del desarrollo de distintas formas de conocer y construir el conocimiento. Es por ello que en las actividades de aprendizaje propuestas en las secuencias se despliega una variedad de estrategias:

- La producción, lectura y análisis de información estadística

- La lectura y la interpretación de fuentes escritas

- La elaboración y la comprobación de hipótesis

- La producción y el análisis de cartografía

- La confrontación de distintas posiciones

- La elaboración de conclusiones propias

- La formalización de fenómenos por medio de la definición propia de conceptos

- La conceptualización de los fenómenos a través de procesos deductivos

- El establecimiento del grado de veracidad de las afirmaciones

La segunda parte del libro, presenta cada una de las secuencias didácticas, que constan de distintas actividades, divididas por dimensiones o aspectos del problema a tratar. La primera secuencia se titula El sector agropecuario latinoamericano y sus paradojas; la segunda secuencia aborda La minería metálica, los nuevos actores y los problemas ambientales. Ambas propuestas de enseñanza están preparadas y diseñadas para que el docente trabaje en el aula con el material, ya que cada actividad propone las consignas a los alumnos con las fuentes y recursos gráficos o cartográficos necesarios para su desarrollo, además del espacio para que los alumnos y alumnas redacten los resultados. 